Original Research Paper

\title{
A DC-DC Circuit Using Boost Converter for Low Voltage Energy Harvesting Application
}

\author{
Nurul Arfah Che Mustapha, A.H.M. Zahirul Alam, Sheroz Khan and Amelia Wong Azman \\ Department of Electrical and Computer Engineering, \\ International Islamic University Malaysia, Kuala Lumpur, Malaysia
}

\author{
Article history \\ Received: 13-05-2015 \\ Revised: $12-05-2015$ \\ Accepted: 29-05-2015 \\ Corresponding Author: \\ Nurul Arfah Che Mustapha \\ Department of Electrical and \\ Computer Engineering, \\ International Islamic University \\ Malaysia, Kuala Lumpur, \\ Malaysia \\ Email: nurularfah@yahoo.com
}

\begin{abstract}
A DC-DC step-up voltage converter is designed to convert a very low voltage supply, $35 \mathrm{mV}$ such as from the thermal energy source from body heat. The converter can generate an output voltage up to $210 \mathrm{mV}$, approximately six imes its initial input voltage over a frequency of $36 \mathrm{GHz}$. The effect of switching transistors, inductor current, rise and fall time is also highlighted. The circuit operates using $2 \mu \mathrm{H}$ inductor and $0.01 \mathrm{fF}$ load capacitor, is simulated using PSpice Simulation tool. This voltage converter is suitable for energy harvesting application in implanted electronic devices.
\end{abstract}

Keywords: Boost Converter, CMOS, DC-DC Converter, Low Input Voltage, Switch Transistor

\section{Introduction}

The trend of portable handheld and remotely implanted devices for monitoring purposes is gradually on the rise. The field of cochlear and neural-implants in the process to be relevant impairment affected diseasepatients will be around the world in the immediate future. The neo-implants sending electrical pulses deep into the brain proper for activating some of the pathways for activating motor control will become a popularly used field. Other commonly used applications are already diverse; ranging from being used in monitoring environmental and oceanic conditions such animal tracking, autonomous flying or moving objects. The energy requirement of such devices is very small, often needing electronic component capable to produce less than $1 \mathrm{~V}$ battery equivalent sources.

The energy from non-conventional ambient sources over the recent past years is harvested to complement or even replace conventional forms of powering methods using batteries. Such devices need a continuous power supply without having to replace the source. Heat from the sun or human body or that generated from industrial engines combined with vibrations generated from the surroundings are becoming serious contenders in producing such battery equivalent sources.

The advantages include reducing maintenance cost and minimizing the chemical waste from batteries while scavenging for useful applications of energy going into waste as discussed in (Anton and Sodano, 2007; Erturk and Inman, 2011; Wang and Yuan, 2008).
The commonly used harvesting transducers from light, vibration or thermal produces very small Voltage $(\mathrm{mV})$ sources, not enough to meet the needs of even very small energy requirement. Often it needs some additional circuitry to step up the energy to supply a minimum power of $1 \mathrm{~V}$. Another associated concern coming from these sources is that of instability when it comes to sensitive electronic applications such as those of aircraft wings. The technique introduced by (Meninger et al., 2001) using ambient sources by energy scavenging rarely provides solution to this problem.

This paper reports on a proposed harvesting technique which converts very small input voltage energy from thermal source of $50 \mathrm{mV}$ or less using the conventional boost converter to store energy into a capacitor with suitable parameters for circuit operation.

The results gathered consist of the following parameters; frequency of the vibrations, the capacitor and inductor value of the booster used. Further, such results show a higher level of stability in the output voltage and potential application in high frequency $(\mathrm{GHz})$ range when compared with what is reported in (Mustapha et al., 2013).

\section{DC-DC Boost Converter Circuit}

Switch power boost converters always give an output voltage greater than its input voltage. A circuit configuration of DC-DC boost circuit consists of inductor, $L$, diode, load capacitor, $C$ and switch circuit, $S_{W}$, is shown in Fig. 1a. Circuit configuration using NMOS transistor, $M_{S}$, is used to replace the switch circuit and diode transistor, $M_{D}$, is used to replace the diode as shown in Fig. 1 b. 


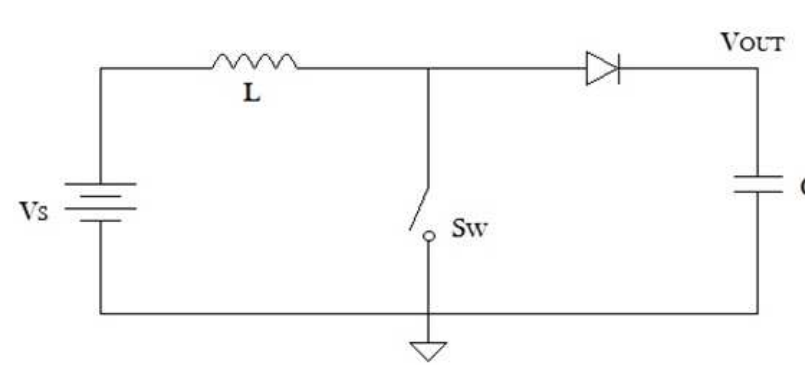

(a)

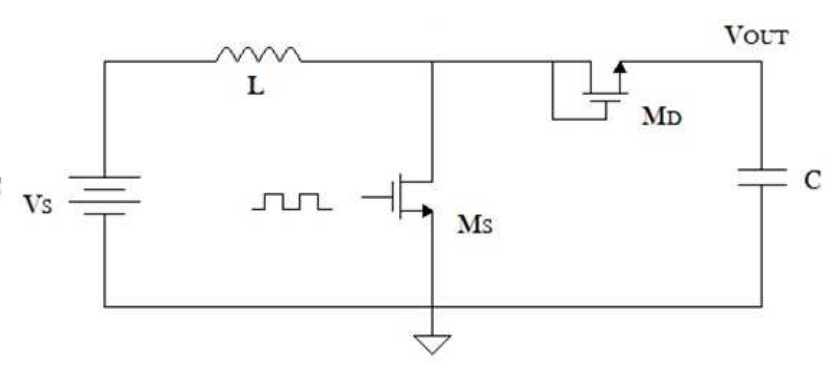

(b)

Fig. 1. (a) A diode boost energy circuit (b) MOSFET as a diode and switching transistor

The transistor switch is turned ON and OFF depending on the mode of operations at $f \mathrm{~s}=1 / \mathrm{T}$. There are two modes of operation for boost converter as reported in (Ang and Oliva, 2005; Daycounter, 2004; Emadi et al., 2009) and the operation can be either one of them at a transition of time: (i) a continuous mode and (ii) a discontinuous mode.

\section{Continuous Mode: When Switch is ON state}

A continuous mode starts when transistor $M_{S}$ is turned $\mathrm{ON}$ and conducting a pulse. The diode transistor at this time is turned OFF and is reversed biased. A charge is being stored and inductor current is drawn into the inductor, $L$. The inductor current, $I_{L}$ will ramp up linearly during the time interval of $t_{O N}$. The relation between the $\mathrm{ON}$ state and the inductor current as in Equation 1:

$V_{I N}=L \frac{I_{2}-I_{1}}{t_{O N}}$ at $0<t \leq t_{O N}$

\section{Discontinuous Mode: When Switch is OFF state}

While in a discontinuous mode, transistor $M_{S}$ is switched OFF. Inductor voltage reverses its polarity in order to maintain its constants current since current in the inductor cannot change instantaneously. Inductor voltage starts to build up its energy and when this charge is higher than the combined energy in transistor diode and load capacitor, the inductor delivers its voltages to the load capacitor through the diode transistor. Voltage at the output capacitor is higher than the input voltage. During this time, $t_{O F F}$ inductor current falls linearly from $I_{2}$ to $I_{1}$ and the state of inductor current, decides the operation mode (Emadi et al., 2009). Equation 2 shows the relation when time is OFF:

$$
V_{\text {OUT }}-V_{I N}=L \frac{I_{2}-I_{1}}{t_{\text {OFF }}} \text { at } t_{\text {ON }}<t \leq T
$$

At every interval of a duty cycle, charge is built up at the load capacitor. For high efficiency purpose, the diode should be ultrafast recovery diode (Daycounter, 2004).

\section{Results}

The charge built up at the output voltage is depending on the switching transistors and the rise and fall time of the switching pulse. In this study, several attempts have been made for testing purposes to get the best parameters values i.e., the inductor value, load capacitance value and working frequency of the design. Calculation has been made before the Spice simulation as shown in Table 1 and result shows the output voltage will increased when the operation frequency rate is increased.

Figure 2 shows the switching transistors pulses at the rate of $0.03 \mathrm{~ns}$ or $33 \mathrm{GHz}$. Figure 3 shows the effect of changing the value of the inductor and frequency rate. Input voltage and load capacitor is maintained the same throughout the simulation testing using $35 \mathrm{mV}$ input.

Substituting Equation 1 and 2 and simplifying the equation, average output voltage is proportional to the duty cycle, $D$ :

$$
V_{\text {OUT }}=\frac{V_{I N}}{1-D}
$$

\section{Discussion}

As soon the transistor switch is at $\mathrm{ON}$ state and the first interval starts, inductor current starts increasing linearly across the diode and there is no current across the diode. Inductor current is continuously decreasing until switch is turned $\mathrm{ON}$.

In the second interval, the switch is not turned ON before current reaches zero, while the inductor current is still decreasing. Diode at this time, does not allow current to go into opposite direction. This explains the sudden peak in diode current and it remains zero at other peak of in Fig. 2. Using Equation 4, different parameters listed in Table 1 and frequency of operations is being tested:

$$
2 \pi f=\frac{1}{\sqrt{L C}}
$$




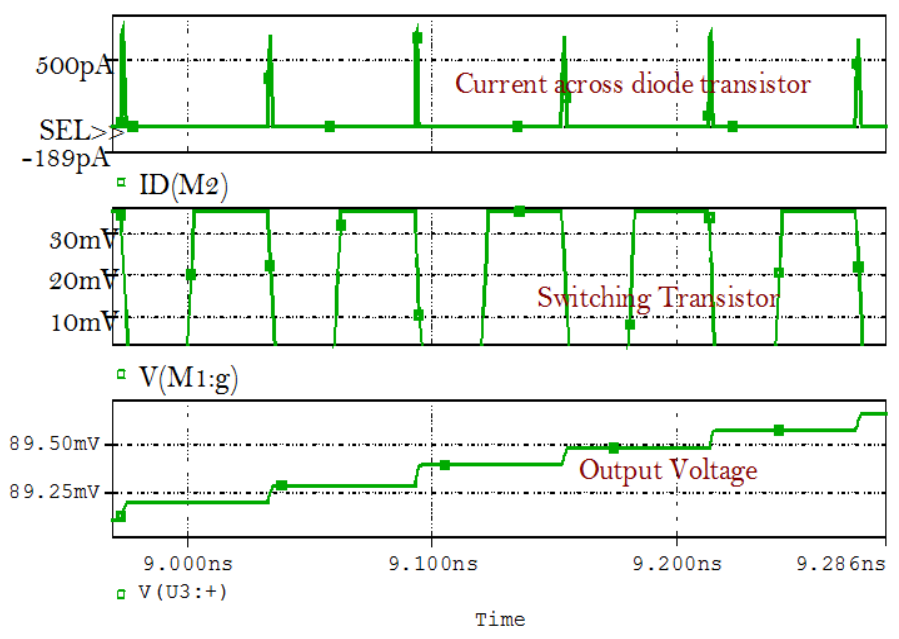

Fig. 2. Simulation output of current, switching transistor and output voltage

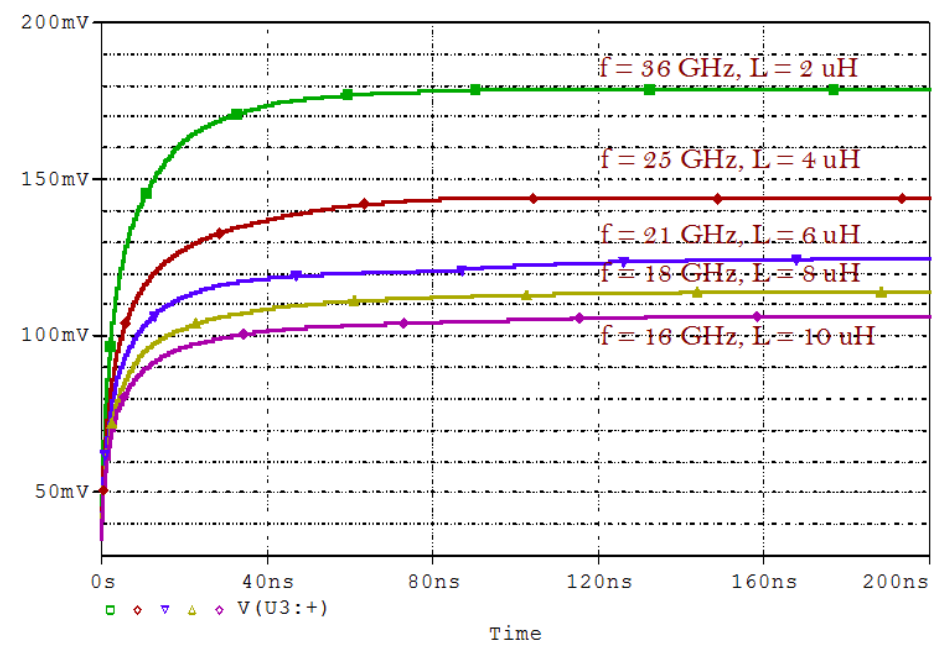

Fig. 3. The effect of changing the inductance value and frequency rate value, when $\mathrm{C}=0.01 \mathrm{f} F$

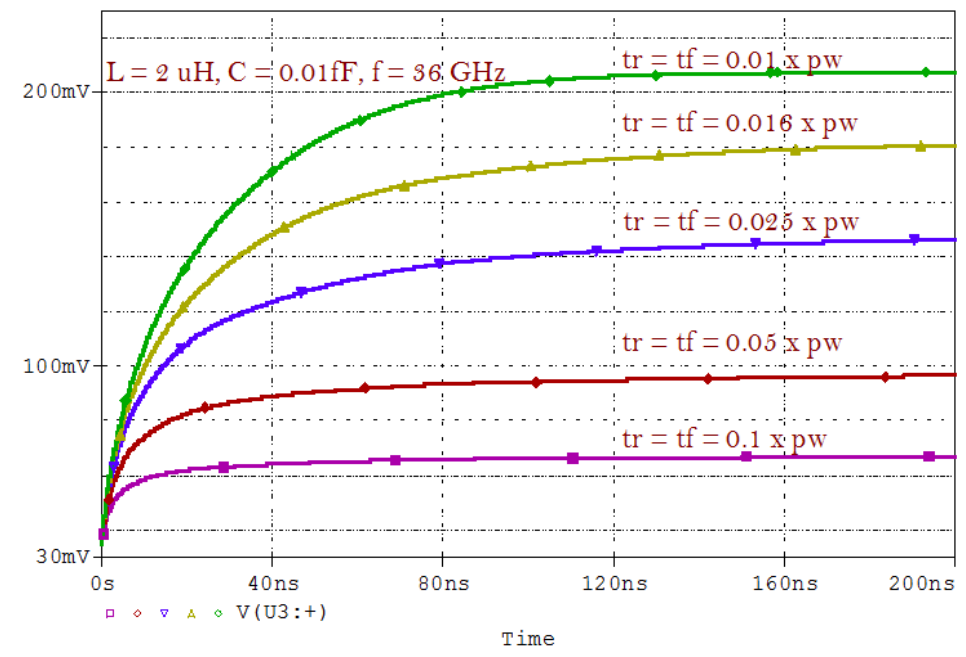

Fig. 4. Effect of rise and fall time to the output voltage with constant pulse width, pw $=0.014 \mathrm{~ns}$ or at $36 \mathrm{GHz}$ rate 
Table 1. Calculation of the inductance and frequency value effect to the output voltage

\begin{tabular}{lllll}
\hline $\mathrm{L}(\mu \mathrm{H})$ & $\mathrm{C}(f \mathrm{~F})$ & $\mathrm{f}(\mathrm{GHz})$ & $\mathrm{T}(\mathrm{ns})$ & $\mathrm{pw}(\mathrm{ns})$ \\
\hline 2 & 0.01 & 35.58 & 0.028 & 0.014 \\
4 & 0.01 & 25.16 & 0.040 & 0.020 \\
6 & 0.01 & 20.54 & 0.049 & 0.024 \\
8 & 0.01 & 17.79 & 0.056 & 0.028 \\
10 & 0.01 & 15.91 & 0.063 & 0.031 \\
\hline
\end{tabular}

Based on the ripple current, $\Delta \mathrm{I}$ of Equation 5, where $\Delta \mathrm{I}=\mathrm{I}_{2}-\mathrm{I}_{1}$. Inductance is inversely proportional to the ripple current:

$\Delta I=\frac{\left(V_{\text {OUT }}-V_{I N}-V_{D}\right)}{L} t_{\text {OFF }}$

The larger the value of ripple current or the peak current, the greater saturation of inductor stress on the transistor (Daycounter, 2004). Thus, it is better to choose lower value of ripple current and consequently will give reasonable value of inductance, $\mathrm{L}$. Increasing the inductance value will eventually decrease the output voltage.

Another parameter contributes to the level of the output voltage is the rise and fall time of the transistor switch, the ON and OFF pulses. A period of complete pulse is equivalent to the double of its pulse width, pw.

By changing the rise and fall time of the pulse, the increment level for the output voltage also increasing. Simulation using Spice at a constant inductance, capacitance, frequency and pulse width with different rise and fall time is shown in Fig. 4. Faster rise and fall time will accumulate faster output level voltage. Hence the minimum rise and fall time make the highest output voltage.

\section{Conclusion}

The circuit is shown to be operating according to specified frequency rate, rise and fall time of the input and by determine the duty cycle of the switching rate. The fastest the switching rate, the greater the output voltage can be obtained. Choosing lower ripple current is better in lowering the inductor's saturation to the diode. By properly design for low voltage requirement, the design parameters are $\mathrm{L}=2 \mu \mathrm{H}, \mathrm{C}=$ $0.01 \mathrm{fF}$ and $\mathrm{f}=36 \mathrm{GHz}$ with input of $35 \mathrm{mV}$ and output voltage of $210 \mathrm{mV}$.

\section{Funding Information}

This paper is funded by Ministry of Higher Education Malaysia through the Research Centre, International Islamic University Malaysia under the Exploratory
Research Grant Scheme ERGS-2013 (Ref: IIUM/504/RES/G/14/3/2/ERGS13-021-0054).

\section{Author's Contributions}

Nurul Arfah Che Mustapha: Tested the circuit design analysis and prepared the manuscript for publication.

A.H.M. Zahirul Alam: Supervised the simulation work, design idea, development of project and implementation.

Sheroz Khan: co-supervised the circuit design idea and development work.

Amelia Wong Azman: co-supervised the organization of manuscript's preparation and content for publication.

\section{Ethics}

This article is original and contains unpublished material. The corresponding author confirms that all of other authors have read and approved the manuscript.

\section{References}

Ang, S. and A. Oliva, 2005. Power-Switching Converters. 2nd Edn., CRC Press, ISBN-10: 0824722450, pp: 568.

Anton, S.R. and H.A. Sodano, 2007. A review of power harvesting using piezoelectric materials (20032006). Smart Mater. Structure, 16: R1-R21. DOI: 10.1088/0964-1726/16/3/R01

Daycounter Inc., 2004. Boost switching converter design equations. Daycounter, Inc.

Emadi, A., A. Khaligh, Z. Nie and Y.J. Lee, 2009. Integrated Power Electronic Converters and Digital Control. 1st Edn., CRC Press, ISBN-10: 1439800707, pp: 350.

Erturk, A. and D.J. Inman, 2011. Piezoelectric Energy Harvesting. 1st Edn., John Wiley and Sons, Chicester, ISBN-10: 1119991358 , pp: 416.

Meninger, S., J.O. Mur-Miranda, R. Amirtharajah, A.P. Chandrakasan and J.H. Lang, 2001. Vibration-toelectric energy conversion. IEEE Trans. Very Large Scale Integrat. Syst., 9: 64-76.

DOI: $10.1109 / 92.920820$

Mustapha, N.A.C., A.H.M.Z. Alam, S. Khan and A.W. Azman, 2013. Parametric analysis for designing low voltage and low frequency energy harvester booster. Proceedings of the IEEE Regional Symposium on Micro and Nanoelectronics, Sept. 25-27, IEEE Xplore Press, Langkawi, pp: 122-125. DOI: 10.1109/RSM.2013.6706488

Wang, L. and F.G. Yuan, 2008. Vibration energy harvesting by magnetostrictive material. Smart Mater. Structure, 17: 1-14.

DOI: $10.1088 / 0964-1726 / 17 / 4 / 045009$ 